\title{
NECESSIDADES FORMATIVAS: EDUCAÇÃO CONTINUADA NAS ESCOLAS DO CAMPO
}

\author{
Deize Heloiza Silva Degrande ${ }^{\mathrm{iD}} 1$ e Alberto Albuquerque Gomes ${ }^{\mathrm{D}} 2$
}

\section{Resumo}

Este artigo é um extrato de uma Dissertação de Mestrado em Educação, que aborda reflexões sobre as necessidades de formação continuada dos docentes atuantes na escola pública do campo. Ao pesquisar esse tema, nos surgiram as seguintes indagações: Como tem ocorrido o processo de formação continuada dos professores das escolas públicas do campo? Quais são suas necessidades de formação continuada? O referencial teórico correspondeu a estudos sobre necessidades formativas, formação continuada e Educação do Campo. Como objetivo geral, buscamos analisar como os docentes da escola do campo entendem suas necessidades formativas. Está pesquisa teve abordagem qualitativa, portanto, optamos pela revisão bibliográfica e pela entrevista semiestruturada, a fim de investigar quais são as necessidades de formação dos professores do campo. Os sujeitos participantes de nossa pesquisa foram cinco professoras atuantes no Ensino Fundamental e no Ensino Médio da Escola Estadual "Luiza Maria da Cruz" da rede estadual de Andradina/SP. As coletas dos dados nos guiaram a resultados que mostram duas principais necessidades profissionais, além da necessidade de se preparar docentes com conhecimento teórico e prático para atuarem nas escolas do campo.

Palavras-chave: Formação Continuada de professores; Escola do campo; Necessidades formativas.

\section{FORMATIVE NEEDS: CONTINUING EDUCATION IN FIELD SCHOOLS}

\section{Abstract}

This article is the extension of a Master's Dissertation that addresses reflections on the continuing education needs of teachers working in public schools in the countryside. When researching this topic, the following questions arose: How has the process of continuing education of teachers in public schools in the countryside taken place? What are your continuing education needs? The theoretical framework corresponded to studies on training needs, continuing education and field education. As a general objective we seek to analyze how the teachers of the field school understand their training needs. This research had a qualitative approach, therefore, we opted for bibliographic review and semi-structured interview, in order to investigate what are the training needs of teachers in the field. The subjects participating in our research were five teachers working in elementary and high

${ }^{1}$ Mestre em Educação pela Universidade Estadual Paulista "Júlio de Mesquita Filho" - UNESP. E-mail: deize_heloiza@hotmail.com.

${ }^{2}$ Professor-Doutor do Programa de Pós-Graduação em Educação da UNESP/Presidente Prudente. E-mail: albertofctunesp1990@gmail.com.

(c) (1) (9) Perspectivas em Diálogo, Naviraí, v. 8, n. 16, p. 41-59, jan./abr. 2021. 
school at the State School "Luiza Maria da Cruz" of the state network of Andradina/SP. The data collection guided us to results that show two main professional needs, in addition to the need to prepare teachers with theoretical and practical knowledge to work in rural schools.

Keywords: Ongoing teacher training; Countryside school; Formative needs.

\section{Introdução}

Este artigo é um extrato das discussões levantadas em nossa Dissertação de Mestrado em Educação. O interesse pelo tema surgiu das minhas vivências como moradora do campo, filha de agricultores e graduada em pedagogia. Cresci acompanhando a trajetória de lutas dos assentados em busca de políticas governamentais que permitissem o acesso de seus filhos a uma escola do campo próxima a seus lares, em especial, a Escola Estadual "Luiza Maria da Cruz" 1.

Localizada no município de Andradina, esta escola há muitos anos vem enfrentando ameaças de fechamento, enquanto, cerca de 426 famílias de três assentamentos vizinhos são obrigadas a matricular seus filhos nas escolas da cidade, localizadas a mais de $30 \mathrm{~km}$ de distância e que não respeitam as especificidades da população camponesa.

Por outro lado, a importância deste artigo também se explica diante a ausência de temas sobre a Educação do Campo nas grades curriculares dos centros de formação inicial para docentes, e nos cursos de especialização lato sensu, fator que justifica nossa pesquisa sobre este tema.

Revendo a história da educação no Brasil, verificamos que a aberturas de escolas do campo ocorreram desde o período da modernização do país, perante a necessidade de conter as pessoas no local em que vivem e evitar o inchamento das cidades (RIOS, 2016), o que influenciou no desenvolvimento de uma Educação Rural de caráter assistencial, buscando o controle da população do campo.

Essa educação amplamente criticada pelos estudiosos e defensores de uma educação que valorizasse as peculiaridades de cada grupo social, pendurou por vários anos; no entanto devido às articulações dos movimentos sociais e das novas conquistas no setor educacional, alguns princípios passaram a ser observados considerando a necessidade da criação de escolas que possuíssem um currículo, um projeto político pedagógico, didáticas e práticas pedagógicas pensadas de acordo a cultura e as relações sociais do meio em que se insere.

O Movimento dos Trabalhadores Rurais Sem Terra (MST) tiveram grande influência nessas reivindicações. Para Molina e Sá (2012, p. 327) as concepções defendidas são de uma escola voltada para o campo, ou seja, escolas do campo que se referem a um projeto de educação, no qual há a formação de sujeitos críticos e capazes de decidir politicamente, em um processo de transformação social.

A partir dessas discussões, os ideais por uma Educação do Campo passaram a fazer parte da agenda política dos governos e da sociedade (Arroyo, 2007). Direitos conquistados passaram a ser apresentado em documentos oficiais, como na Lei de Diretrizes e Bases da Educação Nacional, no 9.394 de 20 de Dezembro de 1996 (LDBEN/96) e no Plano Nacional de Educação (PNE / 2001-2010).

\footnotetext{
1. Nome Fictício. Os nomes dos sujeitos entrevistados e da escola pesquisada foram omitidos nesta dissertação, em virtude dos requisitos estabelecidos pelo Comitê de Ética. Está pesquisa é aprovada pelo Comitê de Ética. Parecer n 3.267.206.
}

(ㄷ) (1) (9) Perspectivas em Diálogo, Naviraí, v. 8, n. 16, p. 41-59, jan./abr. 2021. 
Mesmo diante a tantas vitórias, inúmeros questionamentos ainda permeiam nossas mentes: Como tem ocorrido o processo de formação continuada dos professores das escolas públicas do campo? Quais são suas necessidades de formação continuada?

Para analisarmos melhor esta realidade selecionamos cinco professoras atuantes no Ensino Médio e no Ensino Fundamental (ciclo II), de uma escola do campo localizada no interior do Estado de São Paulo, a qual chamaremos de Escola Estadual "Luiza Maria da Cruz", com o objetivo de analisar como os docentes da escola do campo entendem suas necessidades formativas.

Arrolamos como objetivo específico para este artigo: relatar a partir da pesquisa realizada, quais são as necessidades de formação dos professores do campo. Para Rodrigues e Esteves (1993), analisar sobre as necessidades formativas é compreender a ausência de algo, que também pode estar em nosso inconsciente sem que o percebamos, por não termos a oportunidade de refletir sobre nossa própria realidade.

Considerando o pressuposto que os professores sentem a ausência de formação adequada, refletiremos mais profundamente sobre o papel do professor e da educação atual em nossa sociedade nas escolas do campo, de forma a compreender a necessidade de preparar profissionais para atuarem nas escolas públicas brasileiras.

\section{Metodologia}

Para construção desse texto utilizamos a pesquisa de carácter qualitativo, pois permite descrever e explicar o contexto educacional em uma determinada realidade, não só levantando dados sobre o fenômeno, mas refletindo de acordo ao objetivo apresentado.

Nossas opções metodológicas foram realizadas mediante a leitura de textos produzidos por Esteban (2010), Lima; Mioto (2007), Lüdke; André (1986), Santos (2004), Bardin (2011), entre outros, através dos quais conseguimos definir as múltiplas significações presentes neste estudo, além de ampliar nossa perspectiva sobre o objeto.

De acordo com Esteban (2010), a pesquisa qualitativa é capaz de renovar nossas suposições sobre o objeto de estudo, através das inúmeras práticas interpretativas possíveis ao ser humano, sem desconsiderar a experiência vivida, 0 contexto social e o lugar em que os fatos acontecem.

Para Esteban (2010, p. 127) a pesquisa qualitativa se define como:

[...] uma atividade sistemática orientada à compreensão em profundidade de fenômenos educativos e sociais, à transformação de práticas e cenários socioeducativos, à tomada de decisões e também ao descobrimento e desenvolvimento de um corpo organizado de conhecimentos.

A pesquisa qualitativa, pressuposto básico dessa pesquisa, tem por característica a descrição, com a finalidade de detalhar e compreender a profundidade do fenômeno e o estabelecimento das relações entre as variáveis (GIL, 
2008). A contribuição dessa escolha para as pesquisas em educação se destaca por proporcionar diferentes visões e opiniões diante a uma realidade já conhecida.

Para iniciar nossa investigação, nos apropriamos da revisão bibliográfica, em busca de materiais que permitem maior aprofundamento e apropriação do tema, fator essencial na trajetória de uma pesquisa, pois traz ao pesquisador um parâmetro daquilo que se tem pesquisado nesta área e qual sua importância no âmbito educacional. De acordo com Santos (2004, p. 66):

A leitura inicial sobre o assunto em dicionários, enciclopédias, introduções e manuais didáticos permitirá, ao menos, que se apurem o sentido de palavras-chave, definições, situação histórica do problema, classificações genéricas, etc. Além disso, o conhecimento genérico obtido por meio desse contato inicial ajudará a distinguir o secundário do essencial e facilitará a delimitação do conteúdo dos temas a investigar.

Assim, a utilização dos materiais acima citados, livros, registros, artigos, teses, dissertações, relatórios governamentais entre outros "[...] é apenas um prérequisito para a realização de toda e qualquer pesquisa [...]" (LIMA; MIOTO, p. 38, 2007), permitindo-nos encontrar informações importantes sobre o assunto de nossa pesquisa.

Para identificar as necessidades formativas dos professores utilizamos como instrumento a entrevista semiestruturada, com a intenção de interagirmos com os professores selecionados e colhermos as opiniões destes acerca dos assuntos que abordamos. Para Rosa e Arnold (2008, p.17):

A entrevista é uma das técnicas de coleta de dados considerada como sendo uma forma racional de conduta do pesquisador, previamente estabelecida, para dirigir com eficácia um conteúdo sistemático de conhecimento, de maneira mais completa possível [...].

[...] podemos afirmar que não se trata de um simples diálogo, mas, sim, de uma discussão orientada para um objetivo definido, que através de um interrogatório, leva o informante a discorrer sobre temas específicos, resultando em dados que serão utilizados na pesquisa.

Nesta perspectiva optamos por essa ferramenta de pesquisa, pois ela permite a contextualização dos diálogos e comportamentos dos sujetos, considerando seus valores e crenças através de um posicionamento reflexivo próprio, sendo de responsabilidade do entrevistador evitar divagações ou aprofundamentos desnecessários.

A grande vantagem de se utilizar a entrevista corresponde à possibilidade de captar imediatamente a informação desejada, com qualquer tipo de pessoa que deseja escolher, mesmo que sejam não alfabetizadas e sobre qualquer assunto (LÜDKE; ANDRÉ, 1986).

Neste trabalho optamos pela entrevista do tipo semiestruturada, pois ela permite adaptarmos nosso roteiro as necessidades do momento que estamos em diálogo com o entrevistado, as questões tornam-se mais flexíveis favorecendo assim respostas mais claras, com explicações de falas incompletas e aprofundamentos naquilo que se busca compreender. 
Considerando esses fatores, escolhemos como sujeitos para nossa entrevista cinco professoras ${ }^{1}$, que possuem contrato efetivo ou de permanência estável e com jornada de trabalho correspondente ou superior a 20 horas semanais. Todas trabalham a mais de três anos na escola "Luiza Marida da Cruz", podendo falar com mais propriedade sobre suas necessidades de formação na escola do campo.

Para melhor sistematização, organizamos o processo de coleta de dados em três momentos: planejamento, execução e análise da entrevista semiestruturada. A primeira correspondeu na elaboração do roteiro, no teste de aplicação e nos agendamentos com cada professor.

A segunda etapa correspondeu à execução da entrevista; para tanto nos deslocamos aos locais previamente combinados com os professores. Inicialmente os docentes foram orientados sobre a importância da nossa pesquisa, em seguida aplicamos o roteiro e ao término pedimos para que relatassem suas impressões sobre a entrevista realizada.

A terceira etapa consistiu em analisar o material coletado, para essa etapa utilizamos os processos de Análise de conteúdo propostas por Bardin (2011). Com todas as gravações realizadas, as escutamos por diversas vezes a fim de facilitar a compreensão e atentarmos a cada trecho. Iniciamos assim a transcrição do áudio, adequando fala e escrita, este momento representa a pré-análise do material.

Nesta etapa, também foi importante substituirmos os nomes verdadeiros por identificadores a fim de preservar o anonimato das envolvidas na pesquisa (LEONE, 2011), com o volume desse material em mãos, iniciamos a exploração do material coletado.

Segundo Bardin (2011), neste momento devemos recortar os trechos das falas que se relacionam, agrupando por temas as informações semelhantes ou as que discordam nas falas das professoras, e os trechos que devemos examinar com mais atenção. Em cada reorganização aproveitamos para anexar comentários com nossas observações pessoais e apontamentos bibliográficos a serem conferidos mais tarde.

Esse procedimento nos possibilitou "[...] manter uma perspectiva de totalidade, sem nos desviarmos do foco de interesse" (LÜDKE; ANDRÉ, 1986, p. 30), partindo do princípio de decompor cada fala a fim de analisar criticamente, tornando os dados inteligíveis e com relações entre si.

Concluída esta etapa, iniciamos o tratamento das informações (BARDIN, 2011), que corresponde à busca de inferências mais aprofundadas sobre cada assunto, por meio de nossas fontes bibliográficas estudadas anteriormente e de novas buscas por explicações aos assuntos. Contudo, foi necessário delimitarmos os temas de maior relevância.

Concluída esta etapa iniciamos a escrita final das interpretações realizadas a partir da fundamentação teórica levantada. Pra Bardin (2011) esses passos são o reflexo da interpretação crítica dos significados, a partir da descrição objetiva dos fatos; cada mensagem colhida possibilita o desvendamento de informações ocultas, permitindo inferir outras informações.

A análise de conteúdo para Bardin (2016, p. 37, grifo do autor) é, portanto um "[...] conjunto de técnicas de análise das comunicações", no qual realizamos a 
interpretação rigorosa das ideias dispostas no material coletado, em busca de desvendar diferentes significados e valores nelas submetidas.

Como já citamos esta pesquisa tem como espaço de investigação a escola "Luiza Maria das Cruz", fundada em 1985, para atender os moradores dos assentamentos recentemente instalados, no município de Andradina, no interior de São Paulo. A escola atende cerca de 426 famílias, em uma área de 9.595,104 ha.

O critério da escolha por essa escola deveu-se à importância que a escola exerce na cultura e na história dos habitantes em seu entorno, além das constantes manifestações da população e dos professores pelo não fechamento desta escola, devido às políticas de diminuição de gastos, sendo a única escola estadual de Ensino Médio do município, localizada no campo.

Atualmente a escola "Luiza Maria da Cruz", atende apenas 51 alunos, possuindo 15 professores (sendo 3 homens e 12 mulheres, correspondendo cerca de $5 \%$ do total de professores da região) e 2 gestores. Há 5 salas de aulas, sendo 2 salas multisseriadas. É notável a presença majoritária de mulheres atuantes nessa escola $(80 \%)$, o que refletiu também em nossa pesquisa.

\section{Formação Continuada: Reflexões sobre as necessidades formativas das professoras do campo}

Diante das inúmeras mudanças na história da educação, a formação continuada dos professores das escolas públicas brasileiras tornou-se objeto de estudos dessa área do conhecimento, centrando-se no domínio do saber e na reflexão sobre a relação teoria e prática, sem prejuízo da titulação dos docentes.

Com a reorganização educacional a partir da LDBEN/96, tornaram-se evidentes as necessidades de incentivo e o oferecimento de cursos de formação continuada aos docentes, para que além da adaptação profissional fosse possível preparar o professor para resolver os problemas gerais que a escola tradicional estava enfrentando. Segundo Gatti (2008, p.58):

[...] a educação continuada foi colocada como aprofundamento e avanço nas formações profissionais. Incorporou-se essa necessidade também aos setores profissionais da educação, o que exigiu o desenvolvimento de políticas nacionais ou regionais em resposta a problemas característicos de nosso sistema educacional.

Nessa perspectiva, as necessidades de atualização e renovação profissional tornaram-se inumeras, ensejando a formulação de soluções rápidas que atendessem as inovações criadas pelas políticas educacionais (GATTI, 2008, p. 58). A formação continuada tornou-se uma condição imprescindível; visando valorizar o trabalho do professor, momentos de formação em serviço foram estabelecidos, tais como os Horários de Trabalho Pedagógico Coletivo (HTPCs) e cursos de extensão e pósgraduação.

A partir disso, a formação continuada tornou-se um fator essencial, pois favoresse ao professor participar ativamente das decisões escolares, partilhando das necessidades levantadas pelo grupo e buscando soluções para as situações problemas, colaborando assim para formação de um ambiente no qual o professor 
possuisse identidade com o lugar que trabalha.

Afirmamos, portanto que a formação continuada é capaz de transformar o ambiente escolar, trazendo-lhe fontes de reflexões bem fundamentadas a fim de transformar o dia a dia escolar e transpor o modelo de ensino mecânico.

Segundo Silveira (1995, p. 26), para se garantir essa transformarção:

[...] é preciso que haja a nossa intervenção na realidade. E isso é possível porque, enquanto seres humanos, somos sujeitos da história. Enquanto os outros seres apenas se conformam às determinações da natureza, nós, pelo contrário, através do trabalho podemos transformar a natureza e também a realidade social de acordo com nossas necessidades.

Entendemos assim, que devemos buscar nossa transformação e de nossa sociedade, a fim de resistir aos impasses do contexto atual, no qual os avanços das políticas educacionais vêm sofrendo retrocesso. É preciso repensar nossa postura como profissionais e os impactos que somos capazes de produzir na sociedade.

A formação continuada não deve ser apenas um processo de qualificações e certificações, que visam o treinamento do professor, mas sim como a oportunidade e o espaço destinado à reflexão crítica da sociedade e a luta pelo conhecimento que faça parte da vida de todas as massas populares e que valorizem a riqueza cultural e histórica de cada grupo social.

Desta forma, entender as necessidades formativas dos docentes é o ponto inicial para a realização de espaços e planejamentos de formação continuada nas escolas, proporcionando ao professor a oportunidade de refletir sobre a construção de suas ações, buscando melhorar suas práticas profissionais a partir de conhecimentos e crenças que vão além da formação inicial (IMBERNÓM, 2004).

Para refletir sobre isso, primeiramente buscamos entender este termo. Segundo Rodrigues e Esteves (1993) o conceito "necessidade" remete-se a algo que cause um desejo, uma vontade ou até a uma falta ou uma exigência na vida do indivíduo. Enquanto a palavra "formativas" surge da necessidade do professor em construir-se constantemente, já que a profissão docente "exige que se continue a estudar durante toda a vida profissional, até mesmo em âmbitos que, nesta etapa de formação, nem sequer suspeitam" (IMBERNÓM, 2000, p. 65).

Para Rodrigues (2006), as necessidades formativas dos professores nem sempre são expostas pelo grupo de profissionais, muitas sugestões, desejos, sentimentos, estão abstratos no "inconsciente" de cada docente. Isto porque, o sujeito somente revela suas impressões e os motivos por meio da reflexão dialógica diante a construção de uma formação continuada ao longo de sua carreira.

Segundo as professoras entrevistadas, quando não havia momentos para reunir os membros da escola, elas não percebiam a necessidade de se discutir os conceitos que envolvem a busca por uma Educação do Campo, os quais permeiam diálogos sobre o agronegócio, biodiversidade, agroecologia, entre outros.

Queremos dizer que, o professor ao atuar e refletir sobre suas ações e sobre toda a esfera que o rodeia, permite-se também a aprender. Para Yamashiro (2008, p. 52), isso ocorre, pois: 
[...] quanto mais espaço os profissionais têm para discutir e deliberar sobre a própria formação, mais se envolvem ao longo do processo de formação. A graduação do envolvimento do profissional, enquanto sujeito do seu próprio processo formativo, é um dos fatores que garante o grau de sucesso da ação formativa. Dessa forma, tanto na etapa de determinação das necessidades formativas como nas de formulação e avaliação da ação formativa, a negociação leva o profissional a um envolvimento menos passivo no processo formativo.

Nesta perspectiva, o professor passa a ser o agente ativo de sua própria formação; em grupo, planejam como ampliarão seu conhecimento e gerenciam o processo de acordo as vivências e necessidades da comunidade. Os professores passam a conhecer o que precisam melhorar, adquirem novas perspectivas e aprofundam-se em discussões construtivas sobre a realidade que o cerca.

A seguir apresentaremos análises feitas aos professores da escola "Luiza Maria da Cruz", a fim de analisar suas necessidades formativas na escola do campo.

\section{Necessidades Formativas dos professores atuantes no campo}

Neste tópico elaboramos reflexões acerca do conteúdo das entrevistas coletadas com as professoras da escola "Luiza Maria da Cruz". Vale ressaltar que as analises aqui feitas estão em constante processo de construção, pois a cada leitura temos uma perspectiva daquilo que venha a ser uma interpretação da realidade.

Selecionamos para está pesquisa cinco professoras:

Quadro 1 - Informações profissionais dos sujeitos da pesquisa - 2019 CARACTERIZAÇÃO DOS PROFISSIONAIS DA EDUCAÇÃO ATUANTES NO CAMPO ${ }^{1}$

\begin{tabular}{|c|c|c|c|c|c|c|}
\hline Cargo/ Série & Formação & Sexo & Idade & Categoria & $\begin{array}{c}\text { Tempo } \\
\text { na } \\
\text { docência }\end{array}$ & $\begin{array}{c}\text { Tempo de } \\
\text { atuação } \\
\text { na escola }\end{array}$ \\
\hline $\begin{array}{l}\text { Maria Oliveira, } \\
\text { professora de } \\
\text { História, Filosofia } \\
\text { e Sociologia no } \\
\text { Ensino Médio. }\end{array}$ & $\begin{array}{l}\text { Licenciada em } \\
\text { História, Filosofia, } \\
\text { Sociologia e } \\
\text { Pedagogia além de } \\
\text { Letras, embora não } \\
\text { atue na área. }\end{array}$ & $\mathrm{F}$ & $\begin{array}{l}49 \\
\text { anos }\end{array}$ & Efetiva & 26 anos & 5 anos \\
\hline $\begin{array}{l}\text { Maria Letícia } \\
\text { Ribeiro, } \\
\text { professora no } \\
\text { Ensino } \\
\text { Fundamental II e } \\
\text { responsável pela } \\
\text { ATPC. }\end{array}$ & $\begin{array}{l}\text { CEFAM, Licenciatura } \\
\text { em Letras. }\end{array}$ & $F$ & $\begin{array}{l}48 \\
\text { anos }\end{array}$ & Estável & 24 anos & 24 anos \\
\hline $\begin{array}{l}\text { Maria Verônica } \\
\text { Oliveira, } \\
\text { professora de } \\
\text { Artes do Ensino } \\
\text { Fundamental II e } \\
\end{array}$ & $\begin{array}{l}\text { CEFAM, Licenciatura } \\
\text { em História, Arte, } \\
\text { Sociologia e } \\
\text { Pedagogia. Pós } \\
\text { Graduada Lato }\end{array}$ & $F$ & $\begin{array}{l}33 \\
\text { anos }\end{array}$ & Efetiva & 15 anos & 8 anos mais \\
\hline
\end{tabular}

${ }^{1}$. Os nomes dos sujeitos são fictícios.

@) (1)@ Perspectivas em Diálogo, Naviraí, v. 8, n. 16, p. 41-59, jan./abr. 2021. 


\begin{tabular}{|c|c|c|c|c|c|c|}
\hline $\begin{array}{l}\text { Ensino Médio e } \\
\text { de Sociologia do } \\
\text { Ensino Médio. }\end{array}$ & $\begin{array}{l}\text { Sensu em } \\
\text { Psicopedagogia e } \\
\text { em Arte e } \\
\text { Educação. }\end{array}$ & & & & & \\
\hline $\begin{array}{l}\text { Ana Maria } \\
\text { Barbosa, } \\
\text { professora de } \\
\text { Matemática do } \\
\text { Ensino Médio. }\end{array}$ & $\begin{array}{l}\text { Licenciatura em } \\
\text { Matemática, } \\
\text { Pedagogia e está } \\
\text { licenciando Letras, } \\
\text { possui pós- } \\
\text { graduação Lato } \\
\text { Sensu em Educação } \\
\text { Especial. }\end{array}$ & $F$ & $\begin{array}{l}36 \\
\text { anos }\end{array}$ & Efetiva & 14 anos & 9 anos \\
\hline $\begin{array}{l}\text { Maria de Lourdes } \\
\text { Pereira, } \\
\text { Professora no } \\
\text { Ensino } \\
\text { Fundamental II e } \\
\text { no Ensino Médio. }\end{array}$ & $\begin{array}{l}\text { Licenciatura em } \\
\text { Letras e } \\
\text { Pedagogia. Pós } \\
\text { Graduada Lato } \\
\text { Sensu em Gestão } \\
\text { Educacional }\end{array}$ & $F$ & $\begin{array}{l}50 \\
\text { anos }\end{array}$ & Estável & 16 anos & 3 anos \\
\hline
\end{tabular}

Fonte: Confeccionado pela autora (2020).

Com exceção da professora Maria Oliveira, que teve seu início de carreira em São Paulo, as demais docentes foram alunas da escola "Luiza Maria da Cruz", fizeram licenciatura nas proximidades e hoje trabalham nesta escola. Elas descrevem que sua relação com a escola do campo surgiu por meio da própria relação com a terra, de participarem dos desafios sociais e de sobrevivência daqueles que trabalham no campo e vivem dele, para elas avanços tem ocorrido, mesmo que agora em proporções menores:

Antigamente no sítio era mais difícil para estudar, porque você não podia ir a qualquer momento à cidade. Não tinha ônibus para tudo. As pesquisas tinham que ser nas bibliotecas da cidade. Não tinha como fazer algumas tarefas, pois na escola e no assentamento não tinha material e um lugar para fazer as pesquisas, então era difícil. $O$ transporte também, antes era mais escasso, hoje não, para o morador do sítio agora é fácil, porque tudo o que eles podem ter na cidade é oferecido na escola do sítio, internet, livros, o transporte é melhor, tudo ficou mais fácil. (Ana Maria Barbosa, 2020).

Para Silveira (1995), mesmo que esses avanços sejam claros, a classe dominante sempre esteve disposta a refrear o desenvolvimento da educação crítica, utilizando-se das outras camadas sociais para manter seus privilégios e oferecer-lhes mínimas recompensas, a fim de fazê-los aceitar suas privações com contentamento.

Desta forma, as escolas do campo apesar de conquistarem melhores recursos de acesso às escolas e de estruturas de seus prédios para melhor atendimento da população, ainda sofrem com as privações do acesso aos bens culturais, como visitas a museus, a lugares históricos, a teatros, entre outros, assim como muitas escolas públicas brasileiras.

Das cinco selecionadas, somente a professora Maria de Lourdes Pereira (2020), não reside no assentamento, sendo a docente moradora urbana com mais tempo de serviço nessa escola, apenas três anos, o que nos remete a analisar a grande rotatividade de professores nessa escola. 
Para ela este fator ocorre devido à dificuldade de acesso à escola, os longos percursos por estrada de terra e os gastos com o transporte, faz com que muitos professores desistam de trabalharem no campo. Para Arroyo et al (2004) a educação no Brasil está passando por um caos geral, se intensificando na escola do campo, devido à falta de prioridade nas políticas públicas destinadas a este público.

A professora Maria de Lourdes declara que não foi sua escolha trabalhar nessa escola, mas confessa que não deseja mais voltar para as escolas da cidade, mesmo já se deparando com melhores propostas de trabalho. Ao ser indagada sobre o motivo, ela diz que adquiriu a identidade dessa escola e quer continuar lutando por ela.

Para Nóvoa (2000, p. 16), a "identidade é um lugar de lutas e de conflitos, é um espaço de construção de maneiras de ser e de estar na profissão", capaz de criar no interior da consciência de cada professor o entendimento de que eles são sujeitos históricos e políticos, dentro de contexto social de desigualdades e interesses econômicos.

Maria de Lourdes (2020) completa dizendo que "A nossa esperança é de um mundo melhor, não só na educação, mas em todo lugar. De forma que as pessoas tenham mais amor [...]". Desta forma, ela nos descreve o desejo de todos os professores e para que isto ocorra, segundo Lima (2013), existe a necessidade de oferecer qualidade no ensino e de instrumentalizar estes sujeitos, a partir de melhores condições de trabalho, acesso à escola, materiais didáticos, salários dignos, materiais adequados, entre outros.

Outro fator segundo Maria Oliveira (2019), traz à prova a atuação do professor e ao tipo de formação recebida desde a formação inicial, que voltada a cumprir as exigências do currículo, não prepara os futuros profissionais para exercerem sua função no campo. Ela completa dizendo que os processos seletivos também seguem uma linha mais técnica, impedindo de verificar o perfil e as aptidões de seus contratados.

Para ela e demais entrevistadas, a prova de seleção dos concursos que participaram para efetivação em sua maioria foram realizadas com perguntas objetivas, sendo incapazes de medir o conhecimento e a destreza do professor em trabalhar com as especificidades do campo, trazendo-Ihes o desejo de migrar para a cidade. Elas comentam que sentiram a falta de uma instrução anterior à sua prática em sala de aula, e que acabaram se adaptando a partir das experiências e do contato com os alunos e comunidade.

Para muitos professores adaptar-se a escola do campo tornou-se um desafio a ser superado devido à falta de formação que os integrasse a diferentes culturas; segundo a professora Maria Letícia Ribeiro (2020), socializar e interagir com a população local é o ponto inicial para qualquer prática profissional bem sucedida.

Sobre a necessidade de melhorar a formação inicial, a professora Maria Verônica Oliveira (2020) diz que esse contato com a população foi fundamental, ela participou de estágios e projetos oferecidos nesta escola do campo, disse que encontrou situações inesperadas e difíceis de serem resolvidas, pois o professor iniciante ainda não conhece ou não refletiu sobre suas ações em momentos conflituosos.

Para Maria Letícia (2020), isto ocorre, pois, fora da faculdade "A realidade é totalmente diferente, não tem nada parecido com as teorias estudadas, tem situações nas quais são necessárias ter um 'jogo de cintura' para lidar com a diversidade de 
conflitos [...]", os quais dependem não só do planejamento de aula do professor, mas de estratégias, técnicas e conhecimentos que se desenvolvem ao longo da profissão.

Ela diz que o professor iniciante chega à escola com muitas ideias, mas sem a precisão de como aplica-las, já que devem ser adaptadas a cada escola, sendo necessário conhecer primeiramente o dia a dia escolar, a história e os sujeitos que a formam, após essa adaptação conseguiremos relacionar a teoria aprendida com as práticas de sala de aula.

Contudo, segundo a professora Ana Maria Barbosa (2020), muitos professores já adentram a escola, desestimulados e apreensivos, devido à desestabilização profissional desde a seleção de professores; essa professora diz que em seus primeiros anos, exercer um contato mais eficiente com os alunos era impossível já que a cada dia ministrava aula em uma escola diferente, e nem sempre em sua área de formação.

Ela explica que esse desejo de estabilização criou a necessidade de buscar concursos para efetivar-se, permitindo assim sua efetivação na escola "Luiza Maria da Cruz", a qual possuía vagas disponíveis na sua área de formação, ela descreve que recebeu apenas orientações básicas sobre os projetos nos quais deveria participar durante o ano letivo, mas que sua adaptação foi mais tranquila do que na escola urbana, por já ter sido estagiária nessa escola e moradora do campo.

Já a professora Maria Oliveira (2019), que anteriormente trabalhava na cidade de São Paulo, confessa que em seu primeiro contato houve estranhamentos e receios:

No primeiro momento eu fiquei um pouco assustada, porque como eu não tinha experiência na estrada, uma estrada difícil, mas quando eu conheci a escola me apaixonei, eu até brinco, digo que a escola deveria um dia se transformar em um recanto para professores cansados [...]. A estrada é os $100 \%$ das dificuldades, o restante são facilidades, porque tudo favorecia, você estava dentro do contexto, entendeu?! Então não precisava falar "ah vou deslocar meu aluno", para mostrar algo pra ele, você estava dentro do contexto, as facilidades eram muitas. A dificuldade que eu encontrei, a única, é chegar até a escola, porque estando lá tudo fluía [...].

Ela enfatiza que a insegurança consistia mais no acesso à escola do que no público de alunos que encontrara; diz ainda que devido à sua experiência anterior com escolas de bairros perigosos, encontrou nesta escola do campo um ambiente de refúgio diante dos problemas urbanos, tornando o obstáculo de acesso pequeno após conhecer os valores culturais e o trabalho dos profissionais dessa escola.

Ferry (2008) explica que é normal o professor fazer suposições e sentir-se desestabilizado frente a uma nova situação, sem ter se preparado para ela na formação inicial, o que dificulta nos primeiros dias de atuação, mas possibilita a reflexão e a organização de novas estruturas psíquicas em buscar de adaptar-se à nova realidade.

Assim, percebemos a necessidade de momentos específicos para capacitação profissional antes e concomitante a atuação em sala. Segundo a professora Maria Verônica (2020) nesta escola é preciso "[...] ter formações mais voltadas para a realidade da escola e buscar fazer um trabalho diferente, porque aqui temos alunos 
trabalhadores, desde crianças, eles possuem uma relação com a terra [...]", e ser possível desenvolver práticas de ensino e aprendizagem que atendam a esses alunos.

A docente Maria Oliveira (2019) completa esta fala dizendo que essas formações continuadas em geral se encontram descontextualizadas frente à realidade da escola do campo, tanto dentro como fora da escola:

Eu não tive formação, então o que a gente tem é experiência do dia a dia, agora formação... Ah vamos formar professor para ele trabalhar um pouco mais a questão do campo, a questão do agronegócio, da agropecuária, essa formação, nós não tivemos, eu ainda não tive, porém eu acho que seria interessante e até mesmo para ajudar, porque o homem do campo ele não tem uma formação, é aquela coisa mesmo da experiência, então talvez quem sabe o professor levando a informação para o filho, chegue até a casa dele, eu acho uma ideia bacana, porém não tivemos, eu acredito que ninguém tenha essa formação, para ir dar aula no campo não.

Ou seja, o professor busca formações que estejam ligadas a sua vida cotidiana, aos assuntos que fazem parte do ambiente que trabalha, e que não estejam ligados ao mercado competitivo, de titulações que não agregam conhecimento e nem a reflexão crítica sobre a prática (CAMACHO, 2014).

Os cursos de formações acessíveis para os professores do campo são os mesmos aos professores da cidade, os quais abordam assuntos gerais. Maria de Lourdes (2020) explica que muitos professores acabam escolhendo cursos aleatórios, devido o desejo de alcançar melhor salário, mas que acabam sentindo um distanciamento entre a prática e a teoria. Para Nóvoa (2017, p. 1121):

Tornar-se professor é transformar uma predisposição numa disposição pessoal. Precisamos de espaços e de tempos que permitam um trabalho de autoconhecimento, de autoconstrução. Precisamos de um acompanhamento, de uma reflexão sobre a profissão [...].

Desta forma, entendemos que tem sido intensificado projetos de formação acelerada, encurtando os espaços de reflexão e de construção do conhecimento, por causa do modelo de produção capitalista, que visa a mercantilização da educação diante a projetos políticos e econômicos (CAMACHO, 2014).

Para essas professoras, os momentos mais construtivos de formação, tanto no interior da escola como nos cursos de formação são aqueles que discutem suas vivências e propõem a resolução de conflitos pelo grupo, no entanto, dizem que é notável a imaturidade e a alienação profissional de muitos docentes, fazendo com que o pensamento crítico se perda nos discursos.

Para elas os encontros de formação que fortalecem a prática educativa dentro da escola do campo, são aqueles que os participantes não sejam apenas os professores ou os alunos, mas quando relacionam a comunidade e profissionais de outras áreas, que não dialoguem apenas sobre os currículos a serem aplicados, mas que contemplem nosso papel como ser humano consciente. De acordo com Caldart (2003, p. 22): 
Uma escola do campo não é, afinal, um tipo diferente de escola, mas sim é a escola reconhecendo e ajudando a fortalecer os povos do campo como sujeitos sociais, que também podem ajudar no processo de humanização do conjunto da sociedade, com suas lutas, sua história, seu trabalho, seus saberes, sua cultura, seu jeito.

Nessa perspectiva, o que os professores do campo buscam, é uma "[...] proposta de formação continuada e um projeto de escola, numa perspectiva dialética e abrangente, que possa romper com a construção epistemológica corrente que nos induz a acreditar que existe uma dicotomia entre campo e cidade". (LIMA, 2013, p. 57).

Percebemos assim, que a importância da formação continuada deve constituirse como forma de apoio ao trabalho docente; esta é a principal forma de "fomentar o desenvolvimento pessoal, profissional e institucional do professorado, potencializando um trabalho colaborativo para mudar a prática" (IMBERNÓN, 2009, p. 49) e sanar suas necessidades de formação.

Após realizar as entrevistas constatamos que $80 \%$ das entrevistadas manifestaram o desejo de dar continuidade em sua formação. Segundo a professora Ana Maria Barbosa (2020), apesar dos problemas acima citados, todo curso realizado tem fortalecido sua formação:

A formação continuada tem me ajudado muito, após a faculdade [de Matemática], eu fiz educação especial, pois agora no Estado nós recebemos alunos de inclusão, em cada classe, cada série, temos um aluno, mesmo aqui na escola no campo, temos pessoas com deficiência, é como na escola da cidade, recebemos todos, não há diferença, e essa pós-graduação me ajudou muito a como ensina-los.

[...] Eu venho me comprometendo, há capacitações opcionais que são oferecidas para os professores do Estado, quando os faço, acabo aprendendo e procurando um pouquinho mais. Às vezes o Estado não oferece, mas também não ficamos paradas, vamos atrás para aprofundar na Educação.

[...] Agora estou fazendo a faculdade de Letras, por mim mesma, não por cobrança, mas por livre escolha, porque eu percebo essa necessidade de melhorar nessa área, para poder agregar no meu currículo e melhorar minha atuação.

Ao perguntar-Ihe sobre quais necessidades formativas gostaria de suprir, tanto ela como as demais professoras apontam dois assuntos: a necessidade de preparar o professor do campo para trabalhar com salas multisseriadas, devido à progressão do fechamento de salas nas escolas do campo e cursos que abordam assuntos referentes à Educação do Campo.

Para Gatti, Barreto e André (2011, p. 200), analisar as necessidades formativas dos docentes é de extrema importância, pois:

O levantamento e a análise das necessidades formativas junto aos docentes é um passo essencial, para que tomem consciência de si em situações de trabalho, de suas crenças, valores, posições ideológicas, politicas, éticas, cientificas, pedagógicas, daquilo que norteia sua ação. 
Permitindo toda equipe, colaborar na construção de soluções para os problemas existentes, por exemplo, a necessidade de formação para atuação nas salas de multisseriamento, para as entrevistadas, não basta oferecer apenas palestras que falem superficialmente sobre os temas, elas declaram que necessitam de entender como se aplica na prática, de ver como são realizadas as estratégias eficientes, e que gostariam de interagir com profissionais que já atuam na área.

Segundo Maria de Lourdes (2020):

[...] sabemos que não existe uma receita pronta e acabada para você estar dentro de uma sala de aula, mas é necessário que haja formações mais voltadas para dentro daquela realidade, principalmente para uma sala multisseriada, pois você trabalha com duas séries ao mesmo tempo. Por exemplo, tenho 070 e $8^{\circ}$ ano juntos. Eu acredito que existe um trabalho diferente para isso, quero aprender a como trabalhar. Eu sei que não tem bem um "como trabalhar", mas precisamos de dicas, e às vezes nós não temos isso. Precisamos de apoio mais voltado para a necessidade do aluno, porque percebemos aqui uma grande defasagem no Ensino Médio, por que eles viram o mínimo desde o infantil.

Nesta perspectiva, Maria Leticia (2020) completa dizendo:

É a tecla que todos os professores batem, se viesse alguém de fora e ensinasse como trabalhar a série multisseriada, é isso que todos querem. Somos cobrados a mostrar melhorias, porque aqui tem poucos alunos, mas não vem ninguém nos ensinar a como dar aula em uma sala multisseriada, queremos que alguém venha dar uma semana de aula na sala multisseriada para ensinar a gente, pois todos que vem aqui só falam o que deveria dar certo e não demostram na prática. Ao invés disso falam: "Aqui é aula particular, aula vip, tem poucos alunos na sala", mas não sabem o que enfrentamos, ninguém vem ajudar, nos ensinar a como trabalhar, e isso é o que procuramos.

Essas falas nos permitem refletir sobre o contexto atual da educação pública brasileira, a escola tem se tornado um ambiente de descontentamentos frente às necessidades do professor, é urgente a melhoria dos cursos e dos momentos de formação profissional dentro e fora da escola, além da construção de projetos que valorizem e qualifiquem esses profissionais de acordo as vivências históricas e culturais de cada grupo social.

Podemos relacionar também ao segundo item elencado como necessidades formativas pelas entrevistadas, a necessidade de se trabalhar os assuntos contextualizados a Educação do Campo. Ao questiona-las sobre essa terminologia, e o porquê de uma educação do campo e não no campo, recebemos a seguinte resposta:

No campo, significa você estar lá, simplesmente estar presente, naquele lugar, você apenas estuda no campo. Agora a educação do campo é mais profunda, ou seja, é o aluno voltado para o campo, é uma educação voltada para aquela realidade. O docente 
deveria ser preparado para isso, mas a maioria dos professores está nesta escola com a cabeça voltada ao modelo proposto à cidade. A mesma coisa do que é ensinado na cidade, é levado para os alunos do campo, e essa aprendizagem acaba ficando vaga para eles. Enfim eles dão aula no campo, mas não dão aula para o campo (Maria Verônica, 2020).

Assim, a Educação do Campo, defende que a função social da escola encontrase em formar pessoas como sujeitos ativos em vivências de transformação social, potencializados pedagogicamente em todas as dimensões de vida. Essa professora nos fala que a educação do campo ultrapassa os limites da escola e passam a construir dentro de cada pessoa, um cidadão participante, parte de seu contexto familiar, social, cultural e histórico.

Para a professora Maria Letícia (2020), a Educação do Campo propõe currículos diferentes de acordo à realidade de cada escola e acrescenta:

[...] a escola do campo precisa ter matérias diferenciadas. Pois se tornou a mesma da cidade, organiza-se da mesma forma, ela só é no campo, mas as matérias são as mesmas, e a cobrança também, eu acredito que precisamos ter dentro das matérias conteúdos ou formas de aplicar distintas por ser no campo, para que o aluno possa conhecer as propriedades da terra, como alqueires, hectares, alguma coisa voltada nesse sentido. Mas não, aqui é igualzinho a da cidade, a cobrança é a mesma, só o nome que diz escola do campo, mas é a mesma coisa, a mesma realidade.

Conforme as falas dessa professora é notável que hoje a função da escola está sendo em cumprir apenas com a transmissão sem valor dos conhecimentos de cada área do conhecimento de forma isolada, como pré-estabelecida pelos currículos, enquanto os conhecimentos que fazem parte do campo estão desaparecendo ou adormecidos no seio das famílias.

Segundo as falas das professoras, é interessante considerar que houve um tempo que tais questões eram abordadas com mais propriedade nas escolas do campo, devido a uma disciplina no currículo regular denominada "Produtos agrícolas", dos quais alunos e professores poderiam participar. Essas aulas possuíam um professor organizador que era responsável em analisar os assuntos referentes ao campo e no contato com a terra que fosse de interesse comum à escola, esses momentos abrangiam aulas práticas, visitas às produções da comunidade, contato com diferentes profissionais e roda de diálogo, no qual a aprendizagem acontecia oralmente.

Os assuntos privilegiavam o conhecimento do morador do campo, a partir de temas como: histórias populares, linguagem e cultura, agroecologia, produção sem agrotóxicos, técnicas sobre o cultivo de plantas, o manuseio com a terra, preservação do meio ambiente, o uso de fertilizantes, produção de hortaliças, entre outros.

A professora Maria Letícia (2020) confessa que nesses momentos professores e alunos aprendiam juntos, conhecimentos que faziam parte de sua própria vida, a 
partir da experiência na horta da escola, no pomar ou no sítio de algum assentado. Para Freire e Nogueira (2005, p. 40-41):

Quando a prática é tomada como curiosidade, então essa prática vai despertar horizontes de possibilidades. As pessoas então fazem de seus discursos um panorama do que deve ser feito. As pessoas descobrem com a prática a sua possibilidade.

Este diálogo livre permite à escola do campo superar o modelo assistencial préestabelecido na sua estrutura de funcionamento, para despertar em seu interior alternativas contra o modelo hegemônico de educação, no qual os mecanismos do capitalismo apenas previam a formação de mão de obra barata e lucro a classe mais favorecida.

Maria de Lourdes (2020) conclui dizendo que mesmo com a ausência dessas experiências, os professores continuam a buscar a superação dessas estruturas, por meio do trabalho colaborativo e de ajuda mútua entre os professores, a equipe escolar e a comunidade, sendo possível reestruturar suas aulas, para que o conhecimento chegue até os alunos, "Porque a gente pode estar substituindo e adicionando um texto, uma música, um exemplo, nós conseguimos ir adaptando, procurando resgatar aquela realidade" (Maria de Lourdes, 2020), meio pelo qual buscam resgatar sua identidade.

Todas as professoras acreditam que para a superação das necessidades formativas aqui destacadas, é preciso desenvolver no interior da escola uma formação docente que privilegie a atuação ativa, não como uma "repetição mecânica dos gestos", mas como a "compreensão do valor dos sentimentos" (FREIRE, 2013), e dos muitos significados que nos rodeiam, permitindo assim o "[...] exercício da criticidade que implica a promoção da curiosidade ingênua à curiosidade epistemológica [...]" (FREIRE, 2013, p. 46), o que conduzirá cada indivíduo à autonomia de pensamento e a transformação pessoal e social.

Enfim, este texto nos traz indicadores que mostram às necessidades de formação continuada dos professores atuantes no campo, como necessidade de desenvolverem-se conhecimentos necessários à docência através da formação inicial e continuada, a melhor articulação entre as teorias e práticas, a interação da escola com a cultura e a história da população local, a necessidade de preparar espaços para as reflexões profissionais, além de se oferecer oportunidades de desenvolvimento da consciência política dos professores sobre os aspectos defendidos pela Educação do Campo.

\section{Considerações finais}

A formação continuada dos professores para atuarem nas escolas públicas brasileiras, com destaque às escolas do campo deve ser repensada de acordo as necessidades formativas desses profissionais, considerando os conhecimentos que procedem e envolvem esse local.

Esse trabalho é um recorte da Dissertação de Mestrado em Educação, que teve por objetivo analisar como os docentes da escola do campo entendem suas necessidades formativas, permitindo-nos descrever a realidade de cinco professoras 
atuantes na Escola Estadual "Luiza Maria da Cruz", frente a reflexões sobre formação continuada.

As entrevistas evidenciaram a carência de formação continuada nas escolas do campo - que considerem os princípios da Educação do Campo - defendendo a construção coletiva de sujeitos ativos em vivências visando à transformação social, para os quais a função da escola é de potencializa-los pedagogicamente em todas as dimensões da vida, pois, a educação do campo é capaz de ultrapassar as barreiras das escolas, criando e despertando em cada cidadão sua autonomia de pensamento crítico e seu desejo de ser participante de seu contexto social, familiar, cultural e histórico, pelos quais a valorização humana não se encontra cercada de interesses da hegemonia econômica, mas na real intenção da escola, em proporcionar a todos o acesso ao conhecimento.

Assim as entrevistas confirmam que são necessárias formações mais direcionadas à realidade dos professores de cada escola, nos quais devem envolver conceitos que privilegiam a construção da identidade dos sujeitos que trabalham no campo, como a agroecologia, o agronegócio, da agricultura familiar, do contato com a terra, entre outros.

Outro aspecto que destacamos é a necessidade de cursos de formação que visem à aprendizagem do professor e a disponibilidade de momentos de formação dentro do ambiente escolar. Infelizmente os cursos de formação estão sendo mercantilizados, abordam os assuntos de forma superficial, levando o professor a escolher o curso de melhor acesso para adquirir apenas títulos profissionais.

Desta forma, desde a formação inicial, prosseguindo na formação continuada destacamos que é vigente a melhor articulação entre as teorias e práticas, preparando o professor para sua atuação em diferentes contextos, proporcionandoIhe a oportunidade de interagir com a cultura e a história que permeia a escola, resgatando juntamente com os alunos a identidade da Educação do Campo.

Por fim, é notável a necessidade de propiciar espaços de formação destinados à reflexão em equipe escolar e com a comunidade; estes momentos foram destacados como fontes para o desenvolvimento da consciência política dos professores e do fortalecimento do processo de humanização da sociedade.

\section{REFERÊNCIAS}

ARROYO, Miguel Gonzalez. Políticas de formação de educadores do campo. Campinas: Cad. Cedes, vol. 27, 2007.

ARROYO, Miguel Gonzalez; CALDART, Roseli Salete; MOLINA, Mônica Castagna. Por uma Educação do Campo. Petrópolis: Vozes, 2004.

BARDIN, Laurence. Análise de conteúdo. 70. ed. São Paulo: Almedina Brasil, 2011.

BARDIN, Laurence. Análise de conteúdo. São Paulo: Almedina Brasil, 2016.

CALDART, Roseli Salete. A Escola do Campo em Movimento. Currículo sem

Fronteiras. V. 3, n.1. Petrópolis: Vozes, 2003. 
CAMACHO, Rodrigo Simão. Paradigmas em disputa na Educação do Campo.

(Tese de Doutorado). Universidade Estadual Júlio Mesquita Filho, Presidente Prudente, 2014. Disponível em:

http://www2.fct.unesp.br/pos/geo/dis_teses/14/dr/rodrigo_camacho.pdf Acesso em: 17 fev. 2020.

ESTEBAN, Maria Paz Sandín. Pesquisa qualitativa em educação: Fundamentos e tradições. Porto Alegre: AMGH, 2010.

FREIRE, Paulo. Prática docente: Primeira reflexão. In: Pedagogia da autonomia: saberes necessários à prática educativa. 47.ed. Rio de Janeiro: Paz e Terra, 2013, p. 23-46.

FREIRE, Paulo. NOGUEIRA, Adriano. Que fazer: teoria e prática em educação popular. 8. ed. Rio de Janeiro: Vozes, 2005.

GATTI, Bernadete Angelina. Análise das políticas pra formação continuada no Brasil, na última década. Revista Brasileira de Educação, v. 13, n 37, jan./fev. 2008. p. $57-70$.

GATTI; Bernadete Angelina; BARRETO, Elba Siqueira de Sá; ANDRÉ, Marli Elisa Dalmazo Afonso de. Políticas docentes no Brasil: um estado da arte. Brasília: UNESCO, 2011.

GIL, Antônio Carlos. Como elaborar projetos de pesquisa. 5. ed. São Paulo: Atlas, 2008.

IMBERNÓN, Francisco. Formação docente e Profissional: Formar-se para a mudança e a incerteza. São Paulo: Cortez, 2009.

LEONE, Naiara Mendonça Necessidades formativas dos professores dos anos iniciais na sua inserção no exercício da docência. (Dissertação de Mestrado). Universidade Estadual Paulista - Faculdade de Ciências e Tecnologia, 2011.

\section{LIMA, Roseli Ferreira. Formação de professores da Escola do Campo em}

Cáceres-MT: identidade em construção. (Dissertação de Mestrado). Universidade de Estado de Mato Grosso, 2013.

LIMA, Telma Cristiane Sasso de; MIOTO, Regina Célia Tamaso. Procedimentos metodológicos na construção do conhecimento científico: a pesquisa bibliográfica. Revista Katalysis, v. 10, p. 35-45, 2007.

LÜDKE, Menga; ANDRÉ, Marli Elisa Damalzo Afonso de. Pesquisa em educação: abordagens qualitativas. São Paulo: EPU, 1986. 
MOLINA, Mônica Castagna; SÁ, Laís Mourão. Educação do Campo. In: CALDART, Roseli Salete; PEREIRA, Isabel Brasil; ALENTEJANO, Paulo; FRIGOTTO, Gaudêncio. Dicionário da Educação do Campo. Rio de Janeiro: Expressão Popular, 2012.

NÓVOA, Antônio. Firmar a posição como professor, afirmar a profissão docente. Cadernos de Pesquisa. v.47 n.166, p.1106-1133 out./dez. 2017.

NÓVOA, Antônio. Os professores: um "novo" objecto da investigação educacional?. In: NOVOA, Antônio. (Org.). Vida de professores. Porto: Porto Editora, 2000. p. 11-17.

RIOS, Roseane Oliveira. O projeto educativo da fundação Odebrecht: um estudo sobre seus fundamentos. (Dissertação de Mestrado). Universidade Estadual Paulista Júlio Mesquita Filho, São Paulo, 2016. Disponível em:

https://repositorio.unesp.br/handle/11449/144595. Acesso em: 17 fev. 2020.

RODRIGUES, Ângela; ESTEVES, Manuela. Análise de necessidades na formação de professores. Portugal: Porto, 1993.

RODRIGUES, Maria Ângela Perpétua. Análises de práticas e de necessidades de formação. Lisboa: Direção-geral de Inovação e de Desenvolvimento Curricular, 2006.

ROSA, Maria Virgínia de Figueiredo Pereira do Couto; ARNOLDI, Marlene Aparecida Gonzales Colombo. A entrevista na pesquisa qualitativa: mecanismos para a validação dos resultados. Belo Horizonte: Autêntica Editora, 2008.

SANTOS, Antônio Raimundo dos. Metodologia científica: a construção do conhecimento. 6. ed. Rio de Janeiro: DPeA, 2004.

SILVEIRA, Renê José Trentin. O professor e a transformação da realidade. Nuances - Revista do Curso de Pedagogia, Faculdade de Ciências e tecnologia UNESP, Presidente Prudente, v.1, n.1, p.21-30, set. 1995.

YAMASHIRO, Carla Regina Calone. Necessidades formativas dos professores do ciclo I do Ensino Fundamental de Presidente Prudente/SP. 2008. $204 \mathrm{f}$. Dissertação (mestrado) - Universidade Estadual Paulista Júlio de Mesquita Filho, Faculdade de Ciências e Tecnologia, 2008. Disponível em: https://repositorio.unesp.br/bitstream/handle/11449/92342/yamashiro_crc_me_pr ud.pdf?sequence=1\&isAllowed=y Acesso em: 06 abr 2020. 